\title{
Original
}

\section{Inhibitory Effects of Tea Catechins on Lipid Peroxidation Induced by Rose Bengal and Blue Light Exposure in Porcine Retinal Homogenate}

\author{
Takako NAKAnishi-UedA ${ }^{1)}$, Yoko TaguchI ${ }^{2)}$, Toshihiko UedA ${ }^{2)}$, \\ Satoshi YANO ${ }^{1)}$, Masaki Aburada ${ }^{3)}$, Tsutomu Shimada ${ }^{3)}$, \\ Ryohei KOIDE $^{2)}$ and Hajime YasuHARA ${ }^{1)}$
}

\begin{abstract}
The effect of fractions extracted from green tea and catechins on lipid peroxidation induced by rose bengal and blue light exposure were investigated using porcine retinal homogenate. Thiobarbituric acid reactive substances (TBARS) were measured as lipid peroxide and expressed as nmol malondialdehyde (MDA) per milligram protein. In the presence of $10 \mu \mathrm{M}$ rose bengal and after 30-minute exposure to blue light, the levels of TBARS in $5 \%$ porcine retinal homogenates was $72.1 \pm 5.7 \mathrm{nmol} \mathrm{MDA} / \mathrm{mg}$ protein. Addition of fractions $(25 \mu \mathrm{g} / \mathrm{mL})$ extracted from green tea significantly decreased the production of TBARS to $32.2 \pm 2.7 \mathrm{nmol} \mathrm{MDA} / \mathrm{mg}$ protein. The inhibitory rates were directly proportional to the concentrations of epicatechin gallate (ECG) and epigallocatechin gallate (EGCG) in the fraction extracted from green tea, but were not proportional to the concentrations of $(+)$ - catechin, epicatechin (EC) or caffeine. The $50 \%$ inhibitory concentration $\left(\mathrm{IC}_{50}\right)$ of the purified ECG, EGCG, EC and $(+)$ - catechin were 3.8, 5.3, 39.0 and $98 \mu \mathrm{M}$, respectively. These results confirm that ECG and EGCG extracted from green tea are mainly responsible for the inhibition of the lipid peroxidation in this system.
\end{abstract}

Key words : lipid peroxidation, blue light, rose bengal, catechin, retinal homogenate

\section{Introduction}

Light in the spectral region between $400-1400 \mathrm{~nm}$ can reach the retina ${ }^{1)}$. Light with a wavelength of less than $400 \mathrm{~nm}$ or greater than $1400 \mathrm{~nm}$ is absorbed by the mammalian ocular media, such as the cornea, aqueous humor, lens, and vitreous humor. Light damages the retina, and it is generally accepted that short wavelengths are significantly more hazardous than longer wavelengths ${ }^{2)}$. Walbarst evaluated the light emitted from ophthalmic instruments for potential ocular hazards from ultraviolet, visible and near-infrared radiation. TheTHreshold Limit Values listed are now widely used as safety guidelines for ophthalmic light equipments ${ }^{3)}$. Recent publications repot that blue (460 $\mathrm{nm}$ peak) light-emitting diode

\footnotetext{
1) Department of Pharmacology, Showa University, School of Medicine, 1-5-8, Hatanodai, Shinagawa-ku, Tokyo, 1428555 , Japan.

2) Department of Ophthalmology, Showa University, School of Medicine.

3) Research Institute of Pharmaceutical Sciences, Musashino University.
} 


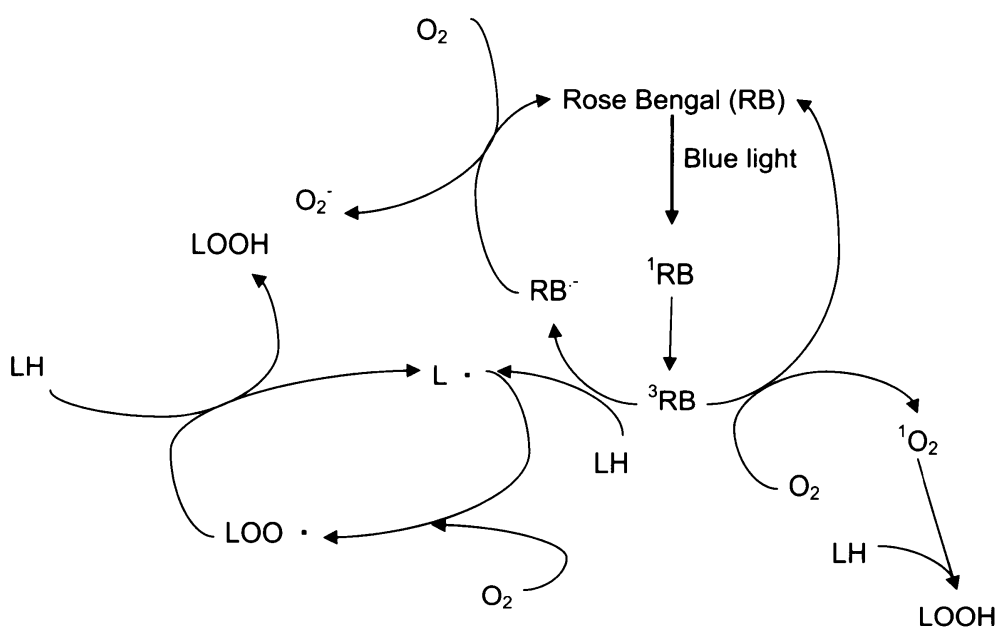

Fig. 1. Scheme of photosensitized lipid peroxidation.

This reaction is initiated by electron or hydrogen atom transfer from a substrate to ${ }^{1} \mathrm{~S}$.

Blue light is $470 \mathrm{~nm}$ LED light. ${ }^{1} \mathrm{RB}$ and ${ }^{3} \mathrm{RB}$ are singlet and triplet rose bengal.

LH : lipid (unsaturated lipid), $\mathrm{L}^{\cdot}$ : lipid alkoxy radical, LOO $\cdot$ : lipid peroxy radical, $\mathrm{LOOH}$ : lipid hydroperoxide.

(LED) light exposure causes retinal damage in rhesus monkeys ${ }^{3.4)}$. Retinal damages, recorded as the resulting lesion scores, was measured form the color fundus photographs, scanning laser tomographs and fluorescein angiogram responses. Lesion scores were evident at 2 and 30 days after exposure greater than $30 \mathrm{~J} / \mathrm{cm}^{2.4)}$, and a marked disruption of photoreceptor cells discs, damaged retinal pigmented epithelial cells (RPE) and loss of RPE melanin were reported with exposure over $60 \mathrm{~J} / \mathrm{cm}^{2,5}$. Retinal light damage occurs via a photochemical reaction ${ }^{6.77}$. Retinal tissues contain a high amount of polyunsaturated fatty acid (PUFA) compared to other tissues ${ }^{8)}$. PUFA is easily oxidized and leads to retinal damage. Molecular oxygen, a sensitizing agent and exciting light initiate the photochemical reaction responsible for retinal lipid peroxidation ${ }^{9)}$ (Fig. 1). Environmental light is a possible cause of age-related macular degeneration $(\mathrm{AMD})^{10)}$ a leading cause of blindness, and the resulting retinal photochemical damage is attributed to oxidative stress ${ }^{11}$.

Green tea is widely consumed in the eastern world. Studies have shown that green tea possesses diverse pharmacological properties that include antioxidative, anti-inflammatory, anticarcinogenic, antiarteriosclerotic and antibacterial effect ${ }^{12-14)}$. Green tea may prevent retinal light damage through its antioxidant activity, and may be an economical and safe treatment for AMD. However, green tea contains several unknown substances, such as caffeine which have adverse effects at high concentrations. The preventive effects might be a result of integral components. In other words, it is possible that the preventive effects would not appear with merely one compound. Thus, it is important to investigate the effect of fractions extracted from green tea as well as the polyphenols in green tea.

In this study, we determined the concentration of catechins in fractions extracted from green tea. The purpose of this study was to determine which green tea components inhibit lipid peroxidation. For this purpose, we investigated the effect of green tea fractions containing different amounts of catechins on lipid peroxidation induced by blue LED light 
exposure and $10 \mu \mathrm{M}$ of the rose bengal as sensitizer in $5 \%$ porcine retinal homogenate.

\section{Materials and Methods}

\section{Retinal homogenate preparation}

The retinas from 50 porcine eyes were obtained from a local slaughterhouse, placed on ice in a dark container and transported within 1 hour to the laboratory for sample preparation. The anterior segment and vitreous humor were removed. The retinas were collected with fine forceps, diced, homogenized with $20 \mathrm{vol} / \mathrm{g}$ of cold distilled water in a glass-teflon homogenizer, and sonicated (Branson Sonifier Cell Disruptor 200, Branson, MI, USA) with 5 -second bursts at $20 \mathrm{~W}$ in an ice bath.

\section{Extraction and fractionation of green tea}

Greentea leaves (the leaves of Camellia sinensis L.), from Yuukisaibai-cha (Yabukita $80 \%$, Kurasawa $10 \%$, others $10 \%$ ) purchased from Nakai-hotoen Co. Ltd. (Kyoto, Japan) was used. The purposes of this fractionation were: 1) to remove caffeine, and 2) to retain the catechins efficiently. The dried tea leaves $(500 \mathrm{~g})$ were extracted with $5 \mathrm{~L}$ of hot methanol (Wako Pure Chemical Co, Osaka, Japan) for 2 hours. The methanolic extract was then dissolved in water $(1.7 \mathrm{~L}$ ) and extracted with $2 \mathrm{~L}$ of $\mathrm{n}$-hexane (Wako Pure Chemical Co., Osaka, Japan) 3 times, followed by $2 \mathrm{~L}$ of $n$-butanol (Wako Pure Chemical Co., Osaka, Japan) 3 times. The water layers were evaporated to obtain the watersoluble fraction $(\mathrm{M}-\mathrm{W}, 29.9 \mathrm{~g})$. The $n$-butanol layer was evaporated to obtain a residue (M-B, $81.5 \mathrm{~g})$. M-B (20.0 g) was partitioned between $400 \mathrm{~mL}$ of chloroform (Wako Pure Chemical Co., Osaka, Japan) and $400 \mathrm{~mL}$ of water. The water layer was concentrated and subjected to Sephadex LH-20 column chromatography and eluted with water followed by $50 \%$ acetone (Wako Pure Chemical Co., Osaka, Japan). These fraction were evaporated to obtain the water eluate (DM-W, 5.6 g) and the $50 \%$ acetone eluate (DM-A50, 12.3 g), respectively.

Analysis of catechins, gallic acid and caffeine in each fraction

$(+)$-Catechin, (-)-epicatechin (EC), (-)-epicatechin gallate (ECG), (-) epigallocatechin gallate (EGCG), caffeine and other chemicals were purchased from Funakoshi Co., Ltd. (Tokyo, Japan).

The HPLC analyses were performed using an LC-10ADvp system with an SPD-10Avp UV-VIS detector and LC solution software (Shimazu, Kyoto, Japan). Chromatographic conditions were as follows : column, Shiseido Capcell pad $\mathrm{C}_{18}(4.6 \mathrm{~mm}$ i.d. $\times 100 \mathrm{~mm}, 3 \mu \mathrm{M})$; mobile phase, (A) $0.1 \% \mathrm{H}_{3} \mathrm{PO}_{4}$ containing $0.1 \% \mathrm{CH}_{3} \mathrm{CN}$ and $5 \% \mathrm{~N}, \mathrm{~N}$-dimethylformamide, (B) $\mathrm{CH}_{3} \mathrm{CN}$; at $0 \mathrm{~min}, \mathrm{~A}: \mathrm{B}$ was $99: 1$, after $40 \mathrm{~min}, \mathrm{~A}: \mathrm{B}$ was $83: 17$; flow rate, $1.0 \mathrm{~mL} / \mathrm{min}$; detector, $280 \mathrm{~nm}$; column temperature, $40^{\circ} \mathrm{C}$.

\section{Incubation conditions}

One hundred $\mu \mathrm{L}$ of $10 \mu \mathrm{M}$ rose bengal (Wako Pure Chemical Co., Osaka, Japan) as sensitizer and $1.8 \mathrm{~mL}$ of $5 \%$ porcine retinal homogenate were placed into a $35 \mathrm{~mm}$ cell culture dish (Corning, Grand Island, NY, USA) and irradiated with a blue $(470 \mathrm{~nm})$ LED light irradiation device (Oki electric Industry Co., Osaka, Japan). The power density was $4 \mathrm{~mW} / \mathrm{cm}^{2}$ and the exposure time was $30 \mathrm{~min}$. The concentration of lipid peroxide in the 
porcine retinal homogenate was determined using the thiobarbituric acid (TBA) assay. To measure the basal levels of TBA reactive substances (TBARS) in the retinal homogenate, $100 \mu \mathrm{L}$ of distilled water was added to the retinal homogenate and analyzed by the TBA assay after $30 \mathrm{~min}$ of irradiation at $37^{\circ} \mathrm{C}$.

Various concentrations of the green tea fractions (M-B, M-W, DM-W, DM-A50) or catechins $((+)$-catechin, EGCG, EC, ECG) were added simultaneously to the retinal homogenates with $10 \mu \mathrm{M}$ rose Bengal, and the retinal homogenates were reassayed to determine the extent of lipid peroxidation inhibition. The total volume of the reaction mixture was $2 \mathrm{~mL}$.

\section{Measurements of thiobarbituric acid reactive substances}

Lipid peroxide concentrations were determined using a modification of the methods described by Okawa et al, which measured the amount of TBARS ${ }^{15)}$. The reaction mixture contained $0.2 \mathrm{~mL}$ of sample, $1.2 \mathrm{~mL}$ of $1 \%$ phosphoric acid (Wako Pure Chemical Co., Osaka, Japan), and $0.4 \mathrm{~mL}$ of $0.6 \%$ thiobarbituric acid (Wako Chemical Co., Osaka, Japan). The mixtures were incubated at $100^{\circ} \mathrm{C}$ for $45 \mathrm{~min}$, and chilled for $15 \mathrm{~min}$ in an ice bath. L-butanol $(1.5 \mathrm{~mL}$ ) (Wako Pure Chemical Co., Osaka, Japan) was added and the reaction was mixed for 5 seconds. After centrifugation at $1500 \times \mathrm{g}$ for $10 \mathrm{~min}, 0.1 \mathrm{~mL}$ of the supernatant layer was removed by pipette, and the absorbance measured in a spectrophotometer (Ultrospec 3300 Pro, Amersham Pharmacia Biotech, Uppsalla, Sweden) at $535 \mathrm{~nm}$. Standards were prepared at concentrations runging from 0.1 to $5 \mu \mathrm{M}$ using 1,1,3,3-tetramethoxypropane (Sigma Chemical Co., St. Louis, MO, USA) and determined as for malondialdehyde (MDA).

Total protein was measured using the Lowry method ${ }^{16)}$ with bovine serum albumin as the standard (Bio-Rad Lab., Heracles, CA, USA). TBARS values were expressed as nanomoles MDA per milligram protein. $\mathrm{IC}_{50}(50 \%$ inhibitory concentration) values were calculated from the green tea fractions or catechin inhibition curves, expressed as a percentage of control.

\section{Statistical analysis}

Samples were analyzed using the Student's t-test. Data are expressed as mean \pm standard error (SE).

\section{Results}

\section{Analysis of green tea fractions}

The concentrations of EC, EGCG and ECG were higher in both the DM-A50 and M-B fractions than in the DM-W and MW fractions. The levels of these components in DM-A50 were nearly two-fold higher than those in the M-B fraction. In contrast, EGCG and ECG were not present in the DM-W and M-W fraction, and EC and catechin were present at very low concentrations. High levels of caffeine were found in the DM-W and M-B fractions (Table 1).

Effect of green tea fractions on blue LED light exposure and $10 \mu M$ rose bengal-induced lipid peroxidation in porcine retinal homogenate

The basal levels of TBARS in the porcine retinal homogenate was $19.2 \pm 0.3 \mathrm{nmol}$ MDA / 
Table 1. Concentrations of catechins and caffeine in the various green tea fractions

\begin{tabular}{lcccc}
\hline & DM-A50 & DM-W & M-B & MW \\
\hline$(+)$-Catechin & 1.1 & 0.3 & 0.8 & 0.04 \\
\hline$(-)$-EC & 6.8 & 0.6 & 4.1 & 0.1 \\
\hline$(-)$-EGCG & 18.9 & - & 10.7 & - \\
\hline$(-)$-ECG & 10.7 & - & 6.6 & - \\
\hline Caffeine & 0.4 & 19.6 & 6.7 & 1.1 \\
\hline
\end{tabular}

The concentrations of $(+)$-catechin, $(-)$-epicatechin (EC), (-)-epigallocatechin gallate (EGCG), (-)-epicatechin gallate (ECG), and caffeine in fractions were determined by HPLC. The data represents the percentages of catechins and caffeine in the total weight of each fraction.

Table 2. TBARS concentration in porcine retinal homogenate after blue LED light exposure for 30 minutes.

\begin{tabular}{lc}
\hline & TBARS $(\mathrm{nmol}$ MDA / mg protein) \\
\hline Without $10 \mu \mathrm{M}$ rose bengal & $19.2 \pm 0.3$ \\
With $10 \mu \mathrm{M}$ rose bengal & $72.1 \pm 5.7^{* *}$ \\
\hline
\end{tabular}

TBARS values ( $\mathrm{nmol} \mathrm{MDA} / \mathrm{mg}$ protein) are expressed as mean $\pm \mathrm{SE}(n=4)$.

${ }^{* *} \mathrm{P}<0.01$ compared to the value without rose bengal.

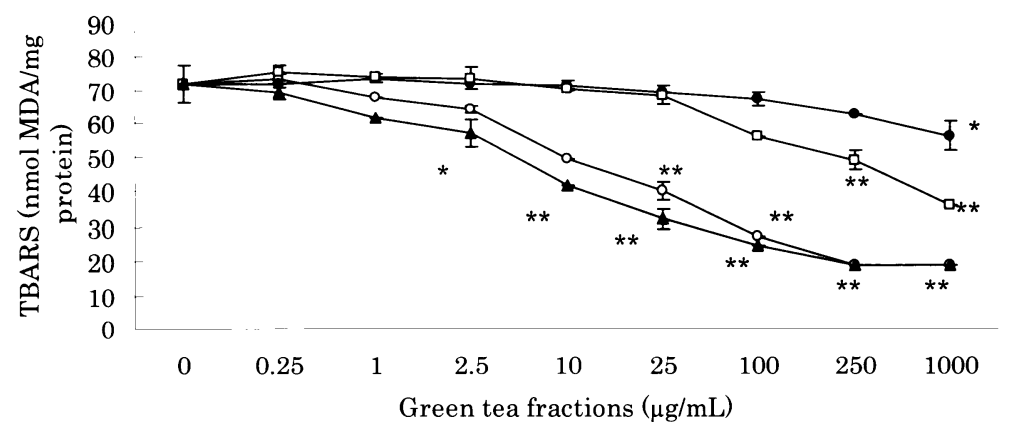

Fig. 2. Effect of green tea fractions on blue light and rose bengal-induced lipid peroxidation in porcine retinal homogenate.

(O): M-W ; $(\square)$ : DM-W ; $(\bigcirc)$ : M-B ; ( $\mathbf{\Delta})$ : DM-A50. Data are mean $\pm \mathrm{SE}$ from five independent experiments. ${ }^{*} \mathrm{P}<0.05,{ }^{* *} \mathrm{P}<0.01 \mathrm{com}-$ pared to the value without green tea fractions $(0 \mu \mathrm{g} / \mathrm{mL})$.

mg protein after $30 \mathrm{~min}$ of blue LED light exposure (control). When $10 \mu \mathrm{M}$ rose bengal was added to the retinal homogenate, TABRS formation was initiated immediately and continued to a maximum at $30 \mathrm{~min}$, at which point the TBARS level in the porcine retinal homogenate had increased significantly to $72.1 \pm 5.7 \mathrm{nmol} \mathrm{MDA} / \mathrm{mg}$ protein $(376 \%$ of control, Table 2). Following the addition of $25 \mu \mathrm{g} / \mathrm{mL}$ DM-A50, and M-B, the blue light and rose bengal-induced TBARS formation significantly decreased to $32.2 \pm 2.7(\mathrm{n}=5, \mathrm{P}<0.01)$, and $40.1 \pm 2.2 \mathrm{nmol} \mathrm{MDA} / \mathrm{mg}$ protein $(\mathrm{n}=5, \mathrm{P}<0.01)$, respectively (Fig. 2) 


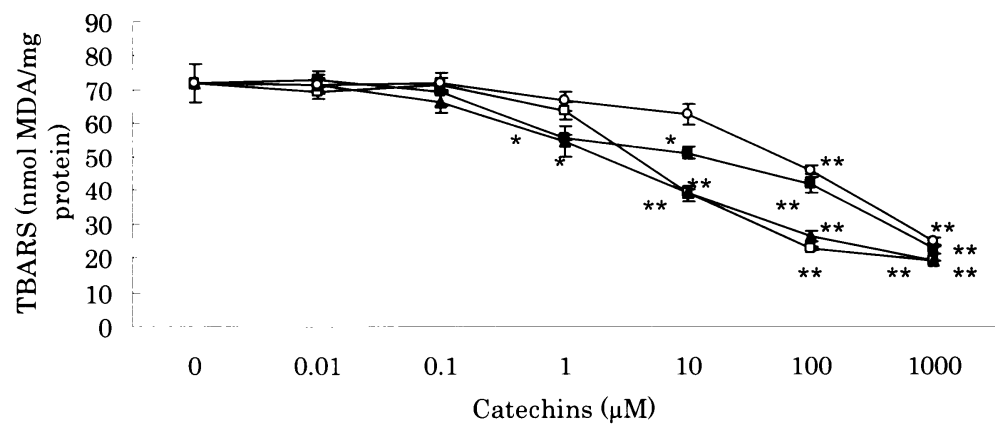

Fig. 3. Effect of tea catechins on blue light and rose bengal-induced lipid peroxidation in porcine retinal homogenate.

(○): $(+)$-catechin; $(\boldsymbol{\square})$ : EC; $(\boldsymbol{\Delta})$ : ECG ; $(\square)$ : EGCG. Data are mean $\pm \mathrm{SE}$ from four independent experiments. ${ }^{*} \mathrm{P}<0.05,{ }^{* *} \mathrm{P}<0.01$ compared to the value without catechins $(0 \mu \mathrm{M})$.

Table 3. $\mathrm{IC}_{50}$ of green tea fractions and catechins

\begin{tabular}{crll}
\hline Green tea fractions & $\mathrm{IC}_{50}(\mu \mathrm{g} / \mathrm{mL})$ & Catechins & $\mathrm{IC}_{50}(\mu \mathrm{M})$ \\
\hline DM-A50 & 7.1 & ECG & 3.8 \\
\hline M-B & 15.0 & EGCG & 5.3 \\
\hline DM-W & 460.0 & EC & 39.0 \\
\hline M-W & 3400.0 & $(+)$-catechin & 98.0 \\
\hline
\end{tabular}

Effect of catechins on blue LED light exposure and $10 \mu \mathrm{M}$ rose bengal-induced lipid peroxidation in porcine retinal homogenate

The blue light and rose bengal-induced TBARS formation was inhibited significantly by $10 \mu \mathrm{M}$ EGCG, ECG and EC to $38.9 \pm 2.0(\mathrm{n}=4, \mathrm{P}<0.01), 39.1 \pm 0.9(\mathrm{n}=4, \mathrm{P}<0.01)$ and $51.0 \pm 1.7(\mathrm{n}=3, \mathrm{P}<0.05) \mathrm{nmol} \mathrm{MDA} / \mathrm{mg}$ protein, respectively (Fig. 3).

\section{$I C_{50}$ calculations}

Table 3 shows the $\mathrm{IC}_{50}$ values of green tea fractions and catechins for blue light and rose bengal-induced TBARS formation. DM-A50 possessed the lowest $\mathrm{IC}_{50}$ of the green tea fractions. ECG and EGCG had the lowest $\mathrm{IC}_{50}$ values of the catechins at $3.8 \mu \mathrm{M}$ and $5.3 \mu \mathrm{M}$, respectively (Table 3 )

\section{Discussion}

In this study, the blue light and rose bengal-induced TBARS formation was inhibited by catechins, especially ECG and EGCG, and was significantly inhibited by the green tea fractions DM-A50 and M-B. The DM-A50 and M-B fractions contains a large amounts of ECG and EGCG (Table 1), therefore these antioxidant activities show higher than those of the $\mathrm{M}-\mathrm{W}$ or DM-W fractions.

The biological effects of light can be explained by at least three fundamental mechanisms, which include photochemical, thermal, and ablation reactions. A photochemical reaction is responsible for the biological effects of environmental illumination, were a sensitizer receives 
a photon from the light and converts it to an excited singlet state. After intersystem crossing and spin inversion to the triplet excited state, triplet state oxygen receives energy from the excited triplet state sensitizer, as this is faster than the rate of internal conversion ${ }^{9)}$ (Fig. 1). Biologically active compounds may be more readily produced from blue light than other visible light. According to Foote ${ }^{17)}$, the absorption of light energy is followed by electron displacement, hydrogen abstraction or energy translation, and the subsequent production of reactive oxygen species (ROS). In the retina, photosensitizing agents that can absorb blue light are porphyrins (cytochrome, hemoglobin), rhodopsin, all-tarans retinal, flavins and A2E (the potential photosensitizer compornet of lipofuscin) ${ }^{18)}$. Lipofuscin is a complex aggregate of material in the RPE formed by ingestion of photoreceptor outer segment, and accumulates with increasing age. The absorbance spectrum of A2E in methanol has a major peak at $435 \mathrm{~nm}$, therefore $\mathrm{A} 2 \mathrm{E}$ can initiated blue light-induced apoptosis in RPE cells ${ }^{19)}$. The adverse effects of blue light on the retina may be due to the existence of blue light absorption molecules, rather than the high energy of blue light. Endogenous and exogenous photosensitizing agents may initiate ROS in the cell upon light exposure and up-regulate signal transduction pathways, and may also start the lipid peroxidation chain reaction in cell membranes (Fig. 1). Quinolone, for example, is converted to an exited state by absorbing blue light energy and produces ROS, and also increase lipid peroxide in porcine retinal homogenate ${ }^{20)}$. This blue light and quinolone-induced lipid peroxidation was suppressed by vitamin $\mathrm{E}$ which acts as a chain-breaking antioxidant in the cell membranes. In the current study, blue light and rose bengal-induced lipid peroxidation was suppressed by DM-A50 and M-B, which contain high amounts of ECG, EGCG and EC. Zhao et al reported that tea catechins had stronger scavenging effect than vitamin $E$ on oxygen free radicals produced from cell systems ${ }^{21)}$. Green tea catechins also have a synergic scavenging effect on the superoxide anion $\mathrm{O}_{2^{-}}$and a combination with a catechins in the ratio EGCG : ECG : EC: $E G C=5: 2: 2: 1$ had the strongest effect ${ }^{22)}$. Therefore, blue light and rose bengal-induced lipid peroxidation in porcine retinal homogenate was suppressed by DM-A50 and M-B. In contrast, EGCG produced $\mathrm{H}_{2} \mathrm{O}_{2}$ in an aqueous solution containing dissolved oxygen ${ }^{14)}$. The concentration of TBARS in $5 \%$ porcine retinal homogenate was not increased by $1 \mathrm{mM}$ EGCG or $1 \mathrm{mM} \mathrm{H} \mathrm{H}_{2}$ after 30 -minute incubation at $37^{\circ} \mathrm{C}$. The porcine retinal homogenate contains catalase and glutathione peroxidase. Therefore, these enzymes may metabolize $\mathrm{H}_{2} \mathrm{O}_{2}$ quickly under the experimental conditions in this study.

The retina contains several antioxidant enzymes and compounds, but their activities and contents decrease with age ${ }^{23)}$. The occurrence of age-related macular degeneration (AMD) increase with age, and it is a leading cause of blindness ${ }^{24)}$. It is possible that environmental light and oxidative stress might contribute to the development of $\mathrm{AMD}^{11}$, and the condition is closely correlated with an increase in lipid peroxide ${ }^{25-29)}$. Therefore, antioxidant treatments may be useful for preventing AMD progression. Lipophilic antioxidants scavenge free radicals in the cell membranes, and are converted into a free radical form. Hydrophilic antioxidants then scavenge the free radicals from the lipophilic antioxidants and are excreted from the cell ${ }^{30)}$. One study has shown that the efficacy of a complex treatment containing zinc and vitamins for age-related eye disease was better than using a single treatment. From these results, it is important to investigate the effects of different fractions and these fractionation methods.

The simple model described in the current study may be employed in the further studies 
to determine the protective effects of various therapeutic agents against retinal light damage.

\section{References}

1) Boettne EA and Wolter JR: Transmission of the ocular media. Invest Ophthalmol 1:776-783 (1962)

2) Ham WT and Mueller HA: Retinal sensitivity to damage from short wavelength light. Nature 260:153-155 (1976)

3) Wolbarsnt ML, Allen R, Beatrice E, Dilori F, Ham JrWT, Hochheimer B, Landry R, Lawwill T, Machemer R, Proenza L, Sliney D, Sperling HG, Stuckand B and Wortman B: Letter to the editor. Invest Ophthalmol Vis Sci 19: 1124 (1980)

4) Dawson W, Nakanishi-Ueda T, Armstrong D, Reitze D, Samuelson D, Hope M, Fukuda S, Matsuishi M, Ozawa $\mathrm{T}$, Ueda $\mathrm{T}$ and Koide $\mathrm{R}$ : Local fundus response to blue (LED and laser) and infrared (LED and laser) sources. Exp Eye Res 73 : 137-147 (2001)

5) Koide R, Nakanishi-Ueda T, Dawson WW, Hope GM, Ellis A, Somuelson D, Ueda T, Iwabuchi S, Fukuda S, Matsuishi M, Yasuhara H, Ozawa T and Armstrong D : Retinal hazard from blue light emitting diode. Acta Soc Ophthalmol Jpn 105: 687-695 (2001) (in Japanese)

6) Noell WK, Walker VS, Kang BS and Berman S: Retinal damage by light in rats. Invest Ophthalmol 5:450473 (1966)

7) Boulnois JL: Phtophysical processes in recent medical laser developments: a review. Laser Med Sci 1:47-66 (1986)

8) Anderson RE and Andrews LD: Biochemistry of photoreceptor membranes in vertebrates and invertebrates. In Visual Cells in Evolution, Wesfall J (Ed), Raven Press, New York, USA, pp 1-22 (1982)

9) Girotti AW : Photodynacic lipid peroxidation in biological systems. Phtochem Photobiol 51 : $497-509$ (1990)

10) Young RW : Solar radiation and age-related macular degeneration. Survey Ophthalmol 32: 252-269 (1988)

11) Beatty S, Koh H, Phil M, Henson D and Boulton $M$ : The role of oxidative stress in the pathogenesis of agerelated macular degeneration. Surv Ophthalmol $45: 115-134$ (2000)

12) Zhao B: The health effects of tea polyphenols and their antioxidant mechanism. J Clin Biochem Netr 38 : 59 68 (2006)

13) Crespy $\mathrm{V}$ and Williamson $\mathrm{G}$ : A review of the health effect of green tea catechins in vivo animal models. $J$ Nutr 134:3431S-3440S (2004)

14) Arakawa $H$, Maeda $M$, Okubo $S$ and Shimamura $T$ : Role of hydrogen peroxide in bactericidal action of catechin. Biol Pharm Bull 27 : 277-281 (2004)

15) Nakanishi-Ueda T, Kamegawa $M$, Ishigaki S, Tsukahara M, Yano S, Wada $\mathrm{K}$ and Yasuhara $\mathrm{H}$ : Inhibitory effect of lutein and pycnogenol on lipid peroxidation in porcine retinal homogenate. $J$ Clin Biochem Nutr 38 : 204-210 (2006)

16) Lowry O, Rosebrough NJ, Farr AL and Randall RJ: Protein measurement with the folin phenol reagent. $J$ Bio Chem 193 : 265-275 (1951)

17) Foote CS : Photoxidation of biological model compouns. In : Oxygen and Oxyradicals in Chemistry and Biology. Rodgers MAJ and Poweres EL (Eds), Academic Press, New York, USA, pp 425-439 (1981)

18) Boulton M, Rozanowska M and Rozanowski B: Retinal photo damage. J Photochem Photobiol B: Biol 64 : 144-161 (2001)

19) Sparrow JR, Nakanishi $K$ and Parish CA: The lipofuscin fluorophore A2E mediates blue light-induced damage to retinal pigmented epithelial cells. Invest Ophthalmol Vis Sci $41: 1981-1989$ (2000)

20) Nakanishi-Ueda T, Shima S, Satoh K, Ueda T, Kamegawa M, Kosuge S, Yoshida M, Uchida S, Mochizuki $\mathrm{N}$, Koide $\mathbf{R}$ and Yasuhara $\mathrm{H}$ : Effect of new quinolones on blue light induced lipid peroxidation in porcine retinal homogenate. In: Proceedings of the 5th International Symposium on Ocular Pharmacology and Therapeutics ISOPT: Monte Carlo, Monaco, March 11-14, 2004, Medimond International Proceedings, Bologna, pp 143-148 (2004)

21) Zhao BL, Li XJ, He RG, Cheng SJ and Xin WJ: Scavenging effect of extracts of green tea and natural antioxidants on active oxygen radicals. Cell Biophys 14:175-184 (1989)

22) Shen SR, Yang XQ, Yang FJ, Zhao BL and Xin WJ : Synergetic antioxidant effect of green tea polyphenols. Tea Sci 13 : 141-146 (1996)

23) Winkler BS, Boulton ME, Gottsch JD and Sternberg P: Oxidative damage and age-related macular degeneration. Mol Vis 5 : 32 (1999)

24) Haddad S, Chen CA, Santangele SL and Seddon JM: The geretics of age-related macular degeneration: a review of progress to data. Surv Ophthalmol $51: 316-363$ (2006)

25) Armstrong D, Abdella N, Salman N, Miller N, Abdel-Rahman E and Bojancyzk M: Relationship of lipid peroxides to diabetic complications: comparison with conventional laboratory test. J Diab Compl 6:116-122 
(1992)

26) Alder VA, Su E-N, Yu D-Y, Cringle SJ and Paula-K Y: Diabetic retinopathy: Early functional changes. Clin Exp Pharmacol Physil 24 : 758-788 (1997)

27) Tanaka Y: Peroxidative reactions in the vitreous as related to diabetic retinopathy. Acta Soc Ophthalmol Jpn $102: 576^{-582}$ (1998) (in Japanese)

28) Verdeho C, Marco P, Renau-Piqueras $\mathrm{J}$ and Pinazo-Duran MD : Lipid perosidation in proliferative vitreoretinopathies. Eye 13 : 183-188 (1999)

29) Spaide RF, Ho-Spaide WC, Browne WR and Armstrong D: Characterization of peroxidized lipids in Bruch' s membrane. Retina $19: 141-147$ (1999)

30) van Leeuewn R, Boekhoorn S, Vingerling JR, Wittemen JC, Klaver CC, Hofman A and de Jong PT: Dietary intake of antioxidants and risk of age-related macular degeneration. JAMA $294: 3101-3107$ (2005)

[Received December 25, 2006 : Accepted January 11, 2007] 